\title{
Use of micellar casein concentrate for Greek-style yogurt manufacturing: Effects on processing and product properties
}

\author{
D. D. Bong and C. I. Moraru ${ }^{1}$ \\ Department of Food Science, Cornell University, Ithaca, NY 14853
}

\section{ABSTRACT}

The objective of this work was to develop and optimize an alternative make process for Greek-style yogurt (GSY), in which the desired level of protein was reached by fortification with micellar casein concentrate (MCC) obtained from milk by microfiltration. Two MCC preparations with 58 and $88 \%$ total protein (MCC-58 and MCC-88) were used to fortify yogurt milk to $9.80 \%$ (wt/wt) protein. Strained GSY of similar protein content was used as the control. Yogurt milk bases were inoculated with $0.02 \%$ (wt/wt) or $0.04 \%$ (wt/wt) direct vat set starter culture and fermented until $\mathrm{pH}$ 4.5. The acidification rate was faster for the MCC-fortified GSY than for the control, regardless of the inoculation level, which was attributed to the higher nonprotein nitrogen content in the MCC-fortified milk. Steady shear rate rheological analysis indicated a shear-thinning behavior for all GSY samples, which fitted well with the power law model. Dynamic rheological analysis at $5{ }^{\circ} \mathrm{C}$ showed a weak frequency dependency of the elastic modulus $\left(G^{\prime}\right)$ and viscous modulus $\left(G^{\prime \prime}\right)$ for all GSY samples, with $G^{\prime}>G^{\prime \prime}$, indicating a weak gel structure. Differences in the magnitude of viscoelastic parameters between the 2 types of GSY were found, with $\mathrm{G}^{\prime}$ of MCC-fortified GSY $<\mathrm{G}^{\prime}$ of control, indicating a different extent of protein interactions in the 2 types of yogurt. Differences were also noticed in water-holding capacity, which was lower for the MCC-fortified GSY compared with the control, attributed to lower serum protein content in the former. Despite some differences in the physicochemical characteristics of the final product compared with GSY manufactured by straining, the alternative process developed here is a feasible alternative to the traditional GSY make process, with environmental and possibly financial benefits to the dairy industry.

Key words: Greek-style yogurt, micellar casein concentrate, rheological parameter, protein fortification

\footnotetext{
Received September 15, 2013

Accepted November 24, 2013.

${ }^{1}$ Corresponding author: cim24@cornell.edu
}

\section{INTRODUCTION}

The rising popularity of Greek-style yogurt (GSY) in recent years is one of the most remarkable events in food production and sales in recent history (Euromonitor International, 2012; Hodkinson, 2013). Greek-style yogurt is traditionally made by straining fermented yogurt curd in a cloth bag to reach the desired solids level by removing acid whey. This step is achieved by mechanically separating the whey from the curd using either a centrifugal separator or membrane filtration (Nsabimana et al., 2005). The production of large quantities of acid whey presents both economic and environmental challenges (Astley, 2013a,b). An alternate make process for GSY that eliminates the acid whey removal step might therefore be attractive to GSY producers. Currently available alternate processes involve fortification of milk with milk protein concentrates to enhance the protein content of the final product. Micellar casein concentrate (MCC) obtained by microfiltration, an emerging protein ingredient that is garnering interest from the dairy industry because of its nutritive value, functionality, and stability during processing (Mulvihill and Ennis, 2003; Nelson and Barbano, 2005; Affertsholt, 2009; Sauer and Moraru, 2012), might be a good candidate for protein fortification of the yogurt milk base.

The change in chemical composition of yogurt milk base as a result of protein fortification has been shown to influence the rheological and physical properties of yogurt (Prentice, 1992; Skriver et al., 1999; Peng et al., 2009; Lee and Lucey, 2010). Several studies have investigated the effects of fortification of milk with whey protein concentrates and caseinates on the physical properties of yogurt (Remeuf et al., 2003; Isleten and Karagul-Yuceer, 2006; Peng et al., 2009; Marafon et al., 2011; Akalın et al., 2012), but comparatively little work has been done to investigate the effect of micellar casein fortification on the make process and properties of yogurt (Peng et al., 2009).

The objectives of this study were to (1) develop and optimize an alternate make process for GSY, in which the desired level of protein is reached by fortification with MCC; and (2) evaluate the effect of MCC fortifi- 
Table 1. Chemical composition of skim milk, MCC-58, and MCC-88 on dry solids basis (wt/wt) ${ }^{1}$

\begin{tabular}{lrrrrrrrr}
\hline & \multicolumn{9}{c}{ Composition $^{3}(\%)$} \\
\cline { 2 - 8 } Sample $^{2}$ & \multicolumn{1}{c}{ TS } & TNP & TP & NPN & CN & Fat & Lactose & Ash \\
\hline Skim milk & 9.35 & 3.38 & 3.19 & 0.19 & 2.67 & 0.13 & 4.97 \\
MCC-88 & 92.90 & 87.93 & 87.51 & 0.42 & 74.74 & 2.11 & 0.68 \\
MCC-58 & 96.99 & 57.64 & 56.35 & 1.29 & 50.81 & 2.16 & 30.54 & 9.47 \\
\hline
\end{tabular}

${ }^{1}$ Values are means of triplicate measurements $(\mathrm{n}=3)$.

${ }^{2}$ MCC-58 and MCC-88 GSY = GSY fortified with micellar casein concentrate at 58 and $88 \%$ total protein, respectively.

${ }^{3} \mathrm{TNP}=$ total nitrogen $\times 6.38 ; \mathrm{TP}=$ true protein $\times 6.38 ; \mathrm{NPN}=\mathrm{TNP}-\mathrm{TP}$.

cation on the chemical and physical properties of GSY compared with GSY made using a traditional straining process.

\section{MATERIALS AND METHODS}

\section{Materials}

Commercial pasteurized skim milk (Crowley Foods, Binghamton, NY) was obtained from a local grocery store and stored at $4^{\circ} \mathrm{C}$ until use. The chemical composition of skim milk was tested at the Dairy One Laboratory (Ithaca, NY), using mid-infrared spectroscopy (AOAC International, 2000; method 972.16). The following parameters were determined: total nitrogen protein (TNP), true protein (TP), TS, CN, fat, lactose, and ash. The average composition of the milk is shown in Table 1. Commercial spray-dried MCC with 88\% TNP (wt/wt; MCC-88) obtained from American Casein Company (Burlington, NJ) and dried MCC with 58\% TNP (wt/wt; MCC-58) produced by David Barbano's research group at Cornell University (Ithaca, NY) and obtained using the methodology described in Hurt et al. (2010) were used for fortification of skim milk. The chemical composition of MCC-58 and MCC88 was tested at the Dairy One Forage Analysis Laboratory (Ithaca, NY), using the methodology described by Beliciu et al. (2012). A commercial sample of plain GSY (Chobani Inc., Norwich, NY) sourced from a local grocery store was used for comparison purposes. The chemical composition of the commercial GSY sample is shown in Table 2.

The chemical composition of the MCC-fortified GSY milk bases and GSY samples were tested at Dairy One Laboratory (Ithaca, NY). Total N (TN) was determined using the Kjeldahl method for milk (AOAC International, 2000; method 991.20), TS by direct forced-air oven drying (AOAC International, 2000; method 990.20), and fat content by using Mojonnier ether extraction (AOAC International, 2000; method 989.05). The lactose content was determined by difference. The determined chemical composition is shown in Table 3.

\section{Starter Culture}

A freeze-dried direct vat set (DVS) yogurt culture (FD-DVS YC-380) containing a mixed strain culture of non-exopolysaccharide (EPS)-producing strains of Streptococcus thermophilus and Lactobacillus bulgaricus was obtained from Chr. Hansen Inc. (Milwaukee, WI). The culture was stored at $-80^{\circ} \mathrm{C}$ until use.

\section{Preparation of GSY Milk Bases}

Skim milk was heated to $40^{\circ} \mathrm{C}$ on a bench-top stirring hot plate (Thermoscientific, Waltham, MA) before preparation of MCC-fortified yogurt milk bases. The fortified yogurt milk bases were prepared by adding the appropriate amount of MCC-58 or MCC- 88 to ob-

Table 2. Chemical composition of Greek-style yogurt (GSY) samples on dry solids basis (wt/wt) ${ }^{1}$

\begin{tabular}{lccccccccc}
\hline & \multicolumn{1}{c}{ Composition $^{3}(\%)$} \\
\cline { 2 - 9 } Sample $^{2}$ & TS & TNP & TP & NPN & CN & CN:SP & Fat & Lactose & Ash \\
\hline Strained GSY (control) & 14.89 & 9.61 & 9.42 & 0.19 & 7.91 & $5.25: 1$ & 0.20 & 4.33 \\
MCC-88 fortified GSY & 15.24 & 9.65 & 9.44 & 0.21 & 7.70 & $5.53: 1$ & 0.16 & 4.32 & 1.11 \\
MCC-58 fortified GSY & 19.40 & 9.90 & 9.58 & 0.32 & 7.99 & $6.30: 1$ & 0.32 & 7.43 & 1.75 \\
Commercial strained GSY & 15.06 & 9.81 & - & - & - & - & 0.24 & 4.03 & 0.88 \\
\hline
\end{tabular}

${ }^{1}$ Values are means of duplicate measurements $(\mathrm{n}=2)$.

${ }^{2}$ MCC-58 and MCC-88 GSY = GSY fortified with micellar casein concentrate at 58 and $88 \%$ total protein, respectively.

${ }^{3} \mathrm{TNP}=$ total nitrogen $\times 6.38$; TP $=\mathrm{TNP}-\mathrm{NPN}$; NPN was calculated based on the NPN content of skim milk and MCC; CN was calculated based on the casein content of skim milk and MCC; serum protein (SP) = TP - CN (CN:SP values represent means of triplicate measurements). 
Table 3. Chemical composition of MCC-58 and MCC-88 fortified Greek-style yogurt (GSY) milk bases, on dry solids basis $(\mathrm{wt} / \mathrm{wt})^{1}$

\begin{tabular}{lccccccccc}
\hline & \multicolumn{10}{c}{ Composition $^{3}(\%)$} & & \\
\cline { 2 - 8 } Sample $^{2}$ & TS & TNP & TP & NPN & CN & CN:SP & Fat & Lactose & Ash \\
\hline MCC-88 & 16.06 & 9.92 & 9.71 & 0.21 & 8.17 & $5.30: 1$ & 0.16 & 4.74 & 1.25 \\
MCC-58 & 19.97 & 9.83 & 9.51 & 0.32 & 8.54 & $8.80: 1$ & 0.36 & 8.14 & 1.64 \\
\hline${ }^{1}$ Values represent means of duplicate measurements $(\mathrm{n}=2)$. \\
${ }^{2}$ MCC-58 and MCC-88 GSY = GSY fortified with micellar casein concentrate at 58 and $88 \%$ total protein, \\
respectively. \\
${ }^{3}$ TNP = total nitrogen $\times$ 6.38; TP = TNP - NPN; NPN was calculated based on the NPN content of skim \\
milk and MCC; CN was calculated based on the casein content of skim milk and MCC; serum protein (SP) \\
$=$ TP - CN.
\end{tabular}

tain mixtures with a target protein content of $9.80 \%$. This protein content was chosen to match the average protein content of the commercial GSY sample (Table 2 ). To allow good dispersion and reconstitution of the MCC in milk, the MCC-88 GSY milk base was subjected to high shear agitation at 6,500 rpm for $20 \mathrm{~min}$ using an Ultra Turrax model T25 fitted with an S25 N-18 G dispersing tool (IKA, Wilmington, NC; Sauer and Moraru, 2012; Sauer et al., 2012). The MCC-58 could be dispersed easily in milk, as indicated by the absence of visible clumps after dispersion of the powder in milk at ambient temperature $\left(20-25^{\circ} \mathrm{C}\right)$. Therefore, high shear agitation was not used and the milk base containing MCC-58 was stirred for 20 min on a stirring plate. The MCC-fortified GSY milk bases were stored at $4^{\circ} \mathrm{C}$ for $18 \mathrm{~h}$ before use to allow sufficient time for hydration of the MCC powder. This rehydration time was in the 15 to $23 \mathrm{~h}$ range reported by Karam et al. (2012) for rehydration of MCC powder.

\section{Preparation of GSY}

To prepare the control GSY, skim milk was heated to $90^{\circ} \mathrm{C}$ for $5 \mathrm{~min}$ on a stirring hot plate (Thermoscientific) and subsequently cooled to $43^{\circ} \mathrm{C}$ in an ice bath. The sample was then inoculated with $0.02 \%$ (wt/wt) or $0.04 \%$ (wt/wt) of starter culture suspension. A $10 \%$ (wt/wt) starter culture suspension was prepared by dispersing $3 \mathrm{~g}$ of the freeze-dried DVS culture in $27 \mathrm{~g}$ of skim milk at $43^{\circ} \mathrm{C}$. The culture was mixed thoroughly in the skim milk and placed in an incubator at $43^{\circ} \mathrm{C}$ (Fisher Scientific, Pittsburgh, PA) for $10 \mathrm{~min}$ to acclimate the starter culture to the incubation temperature before inoculation. After inoculation, the GSY milk bases were placed in an incubator (Fisher Scientific) at $43^{\circ} \mathrm{C}$. The $\mathrm{pH}$ of the GSY samples was measured hourly at $43^{\circ} \mathrm{C}$ using an Accumet Excel XL20 pH meter (Fisher Scientific) calibrated at the measurement temperature before use. When the $\mathrm{pH}$ of the GSY samples reached
4.5, fermentation was arrested by cooling the samples to $\leq 10^{\circ} \mathrm{C}$ (measured in the center of the product) in an ice bath for approximately $30 \mathrm{~min}$. The GSY samples were subsequently subjected to a low shear stirring for $10 \mathrm{~s}$ using a hand mixer (Heritage Series model 2551, Sunbeam Inc., Neosho, MO). After that, $300 \mathrm{~g}$ of the yogurt sample was strained using cheesecloth for 18 to $21 \mathrm{~h}$ at $4^{\circ} \mathrm{C}$ in a refrigerator (Fisher Scientific), to obtain strained GSY with a target protein content of $9.80 \%$ (wt/wt). To reach the target protein content, the amount of whey that had to be drained from the yogurt was established using a mass balance. The strained GSY control samples were subsequently evaluated for their chemical, physical, and rheological properties.

To prepare the MCC-fortified GSY, the MCC-58 and MCC-88 GSY milk bases were subjected to similar thermal treatment, inoculation, and incubation conditions as the control sample. Similar to the control sample, incubation was stopped at $\mathrm{pH} 4.5$ and the yogurt was subjected to low shear mixing for $10 \mathrm{~s}$ using a hand mixer. The MCC-58 and MCC-88 GSY samples were stored at $4^{\circ} \mathrm{C}$ for $24 \mathrm{~h}$ before conducting chemical, physical, and rheological analyses.

\section{Rheological Characterization of GSY}

The rheological properties of the GSY samples were characterized using a dual-transducer Advanced Rheometric Expansion System (ARES) strain-controlled rheometer (TA Instruments, New Castle, DE), in conjunction with the Orchestrator data collection and analysis software (TA Instruments). A parallel-plate geometry (25-mm-diameter Teflon plates) with a 1-mm gap was used for testing, and temperature control was ensured using a Peltier heating system. For each of the rheological parameters described in the subsequent section, approximately $1 \mathrm{~g}$ of sample was gently loaded onto the bottom plate of the rheometer. A 1-min temperature equilibration and relaxation step was allowed 
before proceeding with a test. Testing was conducted at $5^{\circ} \mathrm{C}$, which is within the range of temperature at which yogurt is usually consumed (Farinde et al., 2009).

Steady rate sweeps were used to characterize the flow behavior of GSY. Strain-controlled, steady shear rate sweeps were conducted at $5^{\circ} \mathrm{C}$, with shear rates between 0.01 and $100 \mathrm{~s}^{-1}$, at a frequency of $1 \mathrm{rad} / \mathrm{s}$, in a clockwise direction. Because all GSY samples had a shear dependent, non-Newtonian behavior across the investigated shear rate range, the term "apparent viscosity" $\left(\eta_{\text {app }}\right)$ was used to describe their resistance to flow.

Dynamic strain sweeps were conducted at a frequency of $1 \mathrm{rad} / \mathrm{s}$ and a temperature of $5^{\circ} \mathrm{C}$. A strain range between 0.01 and $5 \%$, which is typical for rheological testing of yogurt (van Marle and Zoon, 1995; Haque et al., 2001; Lee and Lucey, 2006; Peng et al., 2009) was used for all GSY samples. Strain sweeps were used to determine the linear viscoelastic region (LVR) of the GSY samples, which is the region where the elastic $\left(\mathbf{G}^{\prime}\right)$ and viscous $\left(\mathbf{G}^{\prime \prime}\right)$ moduli are independent of the applied strain. Dynamic frequency sweeps were conducted between 1 and $100 \mathrm{rad} / \mathrm{s}$, at a strain level in the upper limit of the LVR. The strain values for each of the GSY samples were as follows: $0.7 \%$ for control and commercial GSY, $0.6 \%$ for MCC-58 GSY, and $0.3 \%$ for MCC-88 GSY. All rheological analyses were performed in triplicate.

\section{Water-Holding Capacity}

The water-holding capacity (WHC) of GSY samples was determined using a modified version of the procedure reported by Sodini et al. (2004). Ten grams of GSY was centrifuged at $1,250 \times g$ for $10 \mathrm{~min}$ at $5^{\circ} \mathrm{C}$ in a refrigerated high-speed centrifuge (Sorvall RC-5B, Thermoscientific, Asheville, NC). The amount of whey expelled during centrifugation $(\mathrm{W}, g)$ was weighed, and WHC calculated as follows: $\mathrm{WHC}=(10-\mathrm{W}) / 10 \times$ $100 \%$. The measurement was carried out in duplicate for each set of experimental replicates.

\section{Titratable Acidity}

Titratable acidity (TA) of the GSY samples was determined using the standard International Dairy Federation procedure (Chandan and O'Rell, 2006). The TA was expressed as grams of lactic acid/100 $\mathrm{g}$ of GSY sample, and was obtained by titrating $9 \mathrm{~g}$ of GSY sample, diluting sample with $18 \mathrm{~g}$ of deionized water, and then titrating with $0.1 \mathrm{~N} \mathrm{NaOH}$. Approximately 0.5 $\mathrm{mL}$ of phenolphthalein was used as an indicator, and titration was conducted until the first permanent shade of pink that lasted for longer than $30 \mathrm{~s}$ was achieved.
The volume of $0.1 \mathrm{~N} \mathrm{NaOH}$ required in the titration was used to determine TA, as follows (Chandan and O'Rell, 2006):

$$
\mathrm{TA}\left(\frac{\mathrm{g} \text { of lactic acid }}{100 \mathrm{~g} \text { of sample }}\right)=\frac{\mathrm{mL} \text { of } 0.1 \mathrm{~N} \mathrm{NaOH}}{10} .
$$

\section{Statistical Analysis}

The statistical software package JMP 9.0 (SAS Institute Inc., Cary, NC) was used for statistical analysis of the experimental data. One-way ANOVA was used to determine significant differences between the experimental GSY samples $(P<0.05)$. Significant differences $(P<0.05)$ between means of dependent variables or measured parameters for the samples were compared using the Tukey-Kramer honestly significant difference (HSD) test.

\section{RESULTS AND DISCUSSION}

\section{Effect of Chemical Composition on the Acidification Profile of GSY}

The chemical composition of the MCC-58 and MCC88 is shown in Table 1 . The main difference between these 2 types of MCC was the degree of removal of the serum phase during diafiltration step of the microfiltration process (Sauer et al., 2012). It is important to note that, after adjusting the GSY milk bases to a similar protein content, MCC-58 GSY had higher TS, lactose, and casein to serum protein $(\mathbf{C N}: \mathbf{S P})$ ratio than did MCC-88 GSY (Table 2). The lactose and casein contents of the yogurt milk base and its CN:SP ratio are important variables that influence the fermentation time of yogurt (Puvanenthiran et al., 2002; Amatayakul et al., 2006). The CN:SP ratio of yogurt also changes during fermentation because the bacteria in the starter culture release proteases capable of hydrolyzing casein molecules (Beshkova et al., 1998; Tamime and Robinson, 2007). The peptides and free AA present in the soluble $\mathrm{N}$ portion of milk are important for growth of the starter bacteria during yogurt fermentation (Neviani et al., 1995; Courtin and Rul, 2004; Tamime and Robinson, 2007).

A consequence of fortification of skim milk with MCC was an increase in the NPN content of the GSY milk base (Table 3). The higher NPN content of MCCfortified GSY samples relative to the unfortified control sample resulted in a slightly shorter fermentation time (Figure 1). The difference in fermentation time was statistically significant $(P<0.05)$ only at the $0.04 \%$ inoculation level; we observed no significant difference in fermentation time between MCC-58 and MCC-88 GSY 
Table 4. $\mathrm{pH}$ and titratable acidity (TA; g of lactic acid/100 g of sample) profiles for Greek-style yogurt (GSY) samples ${ }^{1}$

\begin{tabular}{lcccc}
\hline Sample $^{2}$ & $\begin{array}{c}\text { Time to reach } \\
\mathrm{pH} 4.5(\mathrm{~min})\end{array}$ & $\begin{array}{c}\text { TA at the end } \\
\text { of fermentation }\end{array}$ & ${\text { Final } \mathrm{pH}^{3}}$ & Final TA $^{3}$ \\
\hline 0.02\% (wt/wt) inoculation & & & & \\
Strained GSY & $305 \pm 16^{\mathrm{abc}}$ & $0.66 \pm 0.02^{\mathrm{a}}$ & $4.26 \pm 0.01^{\mathrm{ab}}$ & $1.50 \pm 0.04^{\mathrm{a}}$ \\
MCC-88 GSY & $255 \pm 0^{\mathrm{bc}}$ & $1.52 \pm 0.03^{\mathrm{b}}$ & $4.32 \pm 0.02^{\mathrm{bc}}$ & $1.72 \pm 0.05^{\mathrm{b}}$ \\
MCC-58 GSY & $320 \pm 10^{\mathrm{ab}}$ & $2.11 \pm 0.03^{\mathrm{d}}$ & $4.35 \pm 0.02^{\mathrm{c}}$ & $2.46 \pm 0.05^{\mathrm{d}}$ \\
040 (wt/wt) inoculation & & & & \\
Strained GSY & $330 \pm 0^{\mathrm{a}}$ & $0.73 \pm 0.03^{\mathrm{a}}$ & $4.26 \pm 0.02^{\mathrm{ab}}$ & $1.68 \pm 0.05^{\mathrm{ab}}$ \\
MCC-88 GSY & $250 \pm 10^{\mathrm{c}}$ & $1.60 \pm 0.03^{\mathrm{b}}$ & $4.25 \pm 0.02^{\mathrm{ab}}$ & $1.62 \pm 0.05^{\mathrm{ab}}$ \\
MCC-58 GSY & $255 \pm 9^{\mathrm{bc}}$ & $1.92 \pm 0.03^{\mathrm{c}}$ & $4.33 \pm 0.02^{\mathrm{bc}}$ & $2.07 \pm 0.05^{\mathrm{c}}$ \\
Commercial GSY & - & - & $4.23 \pm 0.02^{\mathrm{a}}$ & $1.60 \pm 0.05^{\mathrm{ab}}$ \\
\hline
\end{tabular}

${ }^{\mathrm{a}-\mathrm{d}}$ Means within a column not sharing a common superscript are significantly different $(P<0.05)$.

${ }^{1}$ Values are mean $\pm \mathrm{SE}(\mathrm{n}=3)$, with the exception of strained GSY with $0.02 \%$ inoculation $(\mathrm{n}=6)$.

${ }^{2}$ MCC-58 and MCC-88 GSY = GSY fortified with micellar casein concentrate at 58 and $88 \%$ total protein, respectively.

${ }^{3}$ Final $\mathrm{pH}$ and TA were measured in strained yogurt with a protein content of $\approx 9.80 \%$; final $\mathrm{pH}$ and $\mathrm{TA}$ in MCC-58 and MCC- 88 samples were measured after storage at $4^{\circ} \mathrm{C}$ for $24 \mathrm{~h}$; final $\mathrm{pH}$ and TA in commercial GSY was measured immediately after retail purchase.

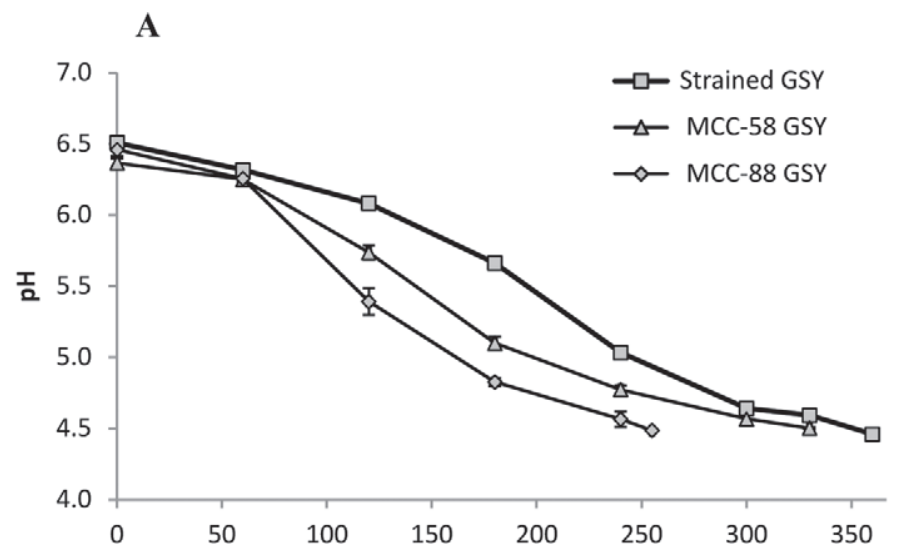

B

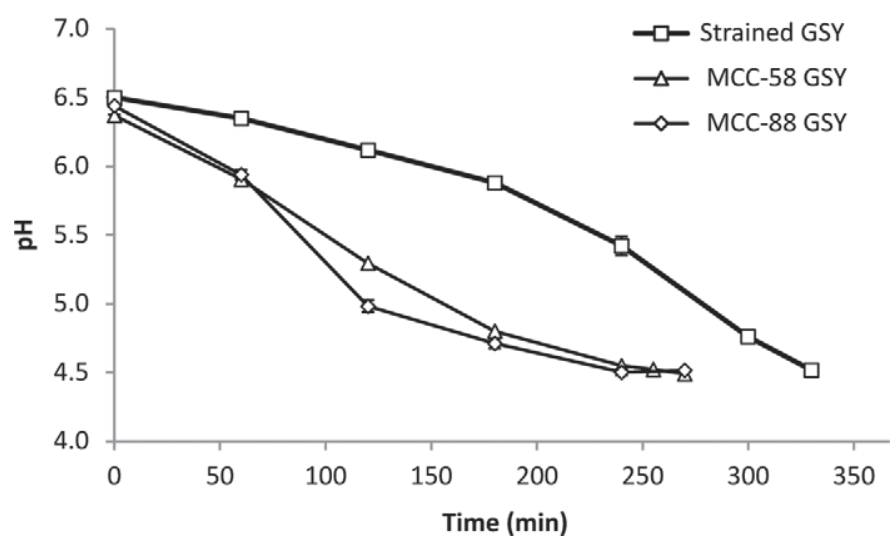

Figure 1. Acidification profiles for Greek-style yogurt (GSY) samples at (A) $0.02 \%$ inoculation level; and (B) $0.04 \%$ inoculation level. Plotted are means of triplicates $(\mathrm{n}=3)$, except for strained GSY at $0.02 \%$ inoculation level $(n=6)$; error bars represent standard errors. MCC-58 and MCC-88 GSY = GSY fortified with micellar casein concentrate at 58 and $88 \%$ total protein, respectively. at the $0.02 \%$ or $0.04 \%$ inoculation level (Table 4 ). Furthermore, despite a significant difference $(P<0.05)$ in the lactose content between the GSY samples fortified with MCC-58 and MCC-88 (Table 2), we observed no significant difference in the fermentation time between the 2 samples. This also supports the conclusion that the main reason for the shorter fermentation time in the MCC-fortified GSY was the higher level of NPN.

The acidification parameters ( $\mathrm{pH}$ and $\mathrm{TA}$ ) for MCC58 and MCC-88 GSY were measured after $24 \mathrm{~h}$ of storage at $4^{\circ} \mathrm{C}$. The $\mathrm{pH}$ of the GSY samples at the end of fermentation before refrigeration storage was 4.50 . The $\mathrm{pH}$ of the control sample was measured after straining, such that its protein content similar to that of the MCC-fortified GSY (Table 2). The final $\mathrm{pH}$ values of the control and MCC-fortified GSY samples were not significantly different $(P>0.05)$ at either inoculation level (Table 4). Damin et al. (2009) reported a small decrease in the $\mathrm{pH}$ of nonfat yogurt after storing the samples at $4^{\circ} \mathrm{C}$ for $24 \mathrm{~h}$, a phenomenon known as postacidification. According to Tamime and Robinson (2007), postacidification during cold storage occurs mainly as a result of the continued conversion of lactose to lactic acid by Lactobacillus bulgaricus. Damin et al. (2009) found that postacidification occurred independently of the level of fortification or the ingredients used in the yogurt milk base. This was also observed in the current study, where differences in composition and solids content of the GSY samples had little effect on the degree of postacidification. We did, however, find a significant difference $(P<0.05)$ in TA values among the experimental GSY samples, both at the end of fermentation and after refrigerated storage. The TA value for the MCC-fortified GSY was significantly higher $(P$ $<0.05)$ than that of the control, at both inoculation 
levels (Table 4). The sample fortified with MCC-58 had the highest TA value. This was expected because of both the higher NPN level and the higher lactose level in the MCC-58 fortified GSY (Table 2), which probably resulted in a greater amount of lactic acid in this particular sample. The peptides in the NPN fraction of milk are reported to have a stimulatory effect on the growth of Streptococcus thermophilus and consequently increase the extent of conversion of lactose to lactic acid during the first few hours of fermentation (Shah, 2003).

\section{WHC of GSY}

The WHC of yogurt is an indicator of its ability to retain serum in the gel structure. The ability of a yogurt product to exhibit minimal whey separation is an important factor for its retail success, because whey separation negatively affects consumer perception (Lee and Lucey, 2010).

Previous studies have shown that when non-EPSproducing strains are used as the starter culture, the $\mathrm{CN}$ :SP ratio of yogurt milk base and TS are important factors that influence the ability of the yogurt gel network to retain water (Harwalkar and Kalab, 1986; Amatayakul et al., 2006; Lee and Lucey, 2010). According to Puvanenthiran et al. (2002), decreasing the $\mathrm{CN}$ :SP ratio in yogurt milk base increases firmness of the fermented yogurt gels. In this study, the WHC of strained GSY sample was significantly higher $(P<$ 0.05 ) than that of the MCC-fortified samples (Table 5), which could be attributed to the lower $\mathrm{CN}$ :SP ratio of the control compared with the MCC-fortified samples. As the CN:SP ratio of the yogurt decreases, the density of the cross-linked protein network in the gel structure increases. This helps to reduce the size of pores in the gel network structure, which consequently hinders the flow of liquid from the gel structure (Puvanenthiran et al., 2002). The combination of high TS and low CN:SP ratio (Table 2) for the control GSY may have resulted in a denser microstructure for the yogurt gel network, which helped immobilize more free water in the gel structure. Furthermore, whey proteins are known to possess high water-binding capacity (Cerning, 1990; Degeest and DeVuyst, 1999). The synergistic effect of a compact yogurt microstructure and whey proteins helped to enhance the WHC of the yogurt gels. The significantly higher $(P<0.05)$ WHC of MCC-58 GSY compared with the MCC-88 sample (Table 5) was mainly attributed to its higher solids content. The WHC of the MCC-58 GSY was similar $(P>0.05)$ to that of the commercial GSY sample, which showed minimal whey separation even after 1 mo of refrigerated storage.

\section{Rheological Properties of GSY}

The rheological properties of all GSY samples were evaluated at the same protein content, because protein content is known to greatly influence the rheological properties of yogurt gels (Lee and Lucey, 2010). Before discussing the data, it is also important to note that MCC-58 and MCC-88 were dried using freeze-drying and spray-drying, respectively. Nonetheless, unpublished data from our laboratory found that the rheological properties of MCC-58 and MCC- 88 dispersions were not affected by the drying method (freeze-drying vs. spray-drying). Therefore, we expected that the drying method of the $2 \mathrm{MCC}$ preparations would not affect

Table 5. Rheological parameters and water-holding capacity (WHC) of the Greek-style yogurt (GSY) samples ${ }^{1}$

\begin{tabular}{|c|c|c|c|c|c|}
\hline \multirow[b]{2}{*}{ Sample $^{2}$} & \multicolumn{4}{|c|}{ Rheological parameter ${ }^{3}$} & \multirow[b]{2}{*}{$\begin{array}{l}\text { WHC } \\
(\%)\end{array}$} \\
\hline & Flow index, $n$ & $\begin{array}{c}\text { Consistency } \\
\text { coefficient, } \\
K\left(\mathrm{~Pa} \cdot \mathrm{s}^{\mathrm{n}}\right)\end{array}$ & $\begin{array}{l}\text { Apparent viscosity } \\
\text { at } 100 \mathrm{~s}^{-1}, \eta_{100}(\mathrm{~Pa} \cdot \mathrm{s})\end{array}$ & $\begin{array}{l}\text { Frequency } \\
\text { dependence } \\
\text { of } \mathrm{G}^{\prime}, m\end{array}$ & \\
\hline \multicolumn{6}{|c|}{$0.02 \%$ (wt $/ \mathrm{wt}$ ) inoculation } \\
\hline Strained GSY & $0.03 \pm 0.02^{\mathrm{a}}$ & $546 \pm 90^{\mathrm{a}}$ & $6.45 \pm 1.47^{\mathrm{ab}}$ & $0.14 \pm 0.003^{\mathrm{a}}$ & $79 \pm 1^{\mathrm{a}}$ \\
\hline MCC-88 GSY & $0.21 \pm 0.02^{\mathrm{c}}$ & $35 \pm 5^{\mathrm{b}}$ & $0.90 \pm 0.09^{\mathrm{d}}$ & $0.13 \pm 0.006^{\mathrm{ab}}$ & $59 \pm 3^{\mathrm{c}}$ \\
\hline Strained GSY & $0.04 \pm 0.02^{\mathrm{a}}$ & $571 \pm 146^{\mathrm{a}}$ & $6.41 \pm 1.51^{\mathrm{a}}$ & $0.14 \pm 0.003^{\mathrm{a}}$ & $80 \pm 2^{\mathrm{a}}$ \\
\hline MCC-88 GSY & $0.27 \pm 0.03^{\mathrm{c}}$ & $45 \pm 16^{\mathrm{b}}$ & $1.42 \pm 0.34^{\mathrm{d}}$ & $0.12 \pm 0.010^{\mathrm{b}}$ & $64 \pm 3^{\mathrm{c}}$ \\
\hline MCC-58 GSY & $0.09 \pm 0.03^{\mathrm{ab}}$ & $176 \pm 41^{\mathrm{c}}$ & $2.52 \pm 0.26^{\mathrm{cd}}$ & $0.13 \pm 0.003^{\mathrm{ab}}$ & $72 \pm 1^{\mathrm{b}}$ \\
\hline Commercial GSY & $0.12 \pm 0.03^{\mathrm{b}}$ & $196 \pm 87^{\mathrm{c}}$ & $3.63 \pm 1.15^{\mathrm{bc}}$ & $0.12 \pm 0.003^{\mathrm{b}}$ & $70 \pm 2^{\mathrm{b}}$ \\
\hline
\end{tabular}

\footnotetext{
${ }^{\mathrm{a}-\mathrm{d}}$ Means within a column not sharing a common superscript are significantly different $(P<0.05)$.

${ }^{1}$ Values are mean $\pm \mathrm{SD}(\mathrm{n}=3)$.

${ }^{2}$ MCC-58 and MCC-88 GSY = GSY fortified with micellar casein concentrate at 58 and $88 \%$ total protein, respectively.

${ }^{3}$ Meaurements were made in strained yogurt with a protein content of $\approx 9.80 \%$, in MCC-58 and MCC- 88 samples after storage at $4{ }^{\circ} \mathrm{C}$ for $24 \mathrm{~h}$, and in commercial GSY immediately after retail purchase.
} 
the rheological properties of the MCC-fortified GSY samples.

Viscosity and Flow Behavior of GSY. The MCC-58 GSY had a higher apparent viscosity $\left(\eta_{\text {app }}\right)$ than MCC-88 GSY over the investigated shear rate range (Figure 2). This was partly due to the higher casein content in the former, and partly to a stronger gel structure due to a high degree of acidification. The higher density of casein molecules in MCC-58 GSY probably allowed for extensive formation of weak hydrophobic interactions between and within casein aggregates in the gel network. The viscosity data at shear rate of $100 \mathrm{~s}^{-1}\left(\boldsymbol{\eta}_{100}\right)$ was used to make direct comparison of viscosity among the GSY samples. This shear rate was chosen because it is associated with processing operations such as pumping and stirring (Steffe, 1996). Strained GSY had a significantly higher $\eta_{100}(P<0.05)$ than MCC-fortified GSY. However, no significant difference $(P>0.05)$ was observed between the $\eta_{100}$ of MCC-58 and MCC-88 GSY (Table 5). The $\eta_{100}$ value for MCC-58 GSY was statistically similar $(P>0.05)$ to that of the commercial GSY sample at both inoculation levels (Table 5).

All GSY samples exhibited shear thinning behavior, with viscosity decreasing as a function of shear rate (Figure 2). Concentrated yogurt has been characterized as a pseudoplastic material in other studies and this behavior was attributed to weak electrostatic and hydrophobic interactions within the yogurt matrix, which are easily disrupted by shear (Abu-Jdayil et al., 2000; Abu-Jdayil and Mohameed, 2002; Mohameed et al., 2004). The power law model was found to be a good fit for the flow behavior of both strained GSY and MCC-fortified GSY, in agreement with other studies on concentrated yogurt (Abu-Jdayil and Mohameed, 2002; Mohameed et al., 2004).

The power law model has the following mathematical form: $\sigma=K(\dot{\gamma})^{n}$, where $\sigma$ is the shear stress $(\mathrm{Pa}), K$ is the consistency coefficient $\left(\mathrm{Pa} \cdot \mathrm{s}^{n}\right), \dot{\gamma}$ is the shear rate $\left(\mathrm{s}^{-1}\right)$, and $n$ is the flow behavior index. The flow behavior index measures deviation from Newtonian flow $(n=$ 1 ), and offers an indication of the rate of structure change with a change in shear rate. The fit for all data sets was very good, with the coefficient of determination $>98 \%$ in all cases. Values for $K$ and $n$ for all samples are presented in Table 5 . The range of $n$ values for the MCC-fortified GSY observed in the study was below the range reported by Sauer et al. (2012) for MCC dispersions with similar protein content. The observed difference was attributed to a difference in structure between the 2 systems, with the MCC-fortified GSY being a weak gel network consisting of casein aggregates linked by weak, noncovalent bonds, including
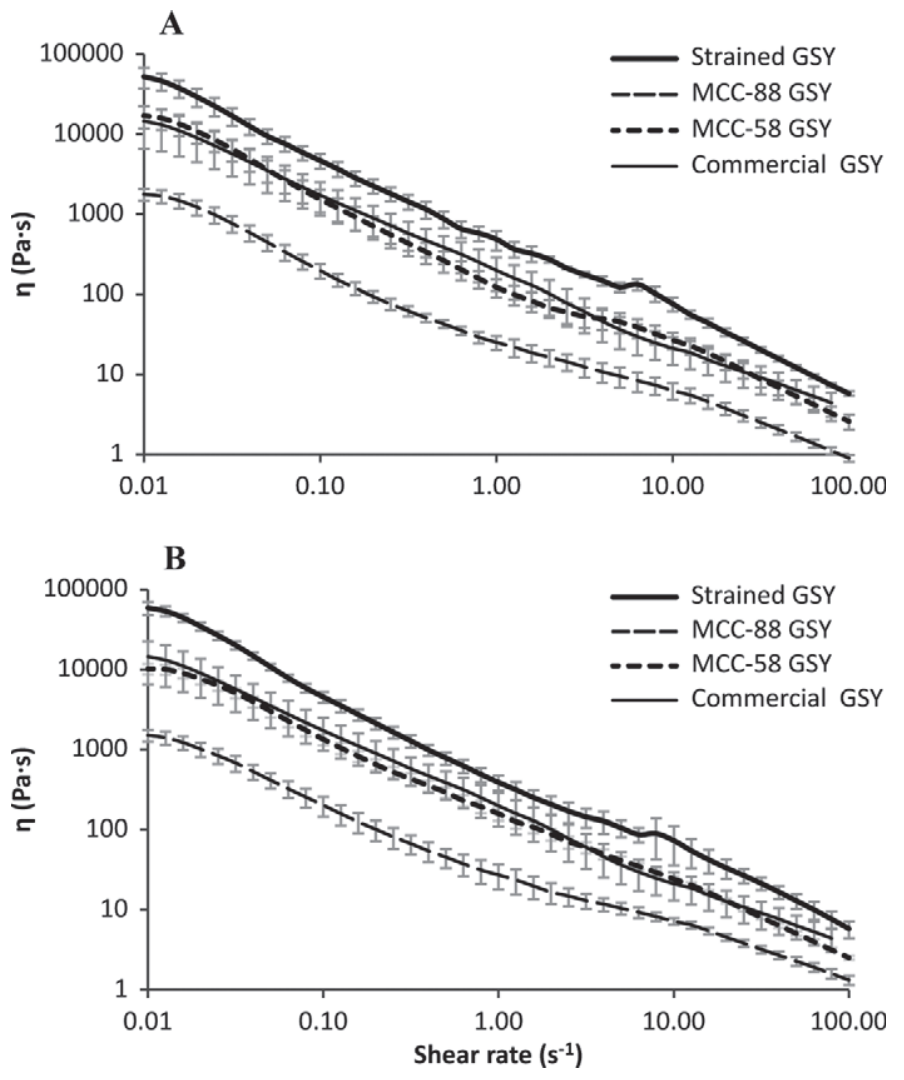

Figure 2. Apparent viscosity $(\eta)$ as a function of shear rate (flow curves) for Greek-style yogurt (GSY) samples at (A) $0.02 \%$ inoculation level; (B) $0.04 \%$ inoculation level. Plotted are means of triplicate measurements $(\mathrm{n}=3)$; error bars represent 1 standard deviation. MCC-58 and MCC-88 GSY = GSY fortified with micellar casein concentrate at 58 and $88 \%$ total protein, respectively.

hydrogen bonds and electrostatic and hydrophobic interactions. In addition, solubilization of colloidal calcium phosphate during yogurt fermentation weakens the internal structure of casein micelles and increases the likelihood of dissociation of casein from the micelles, causing a partial loosening of bonds within and between casein molecules (Lee and Lucey, 2010). Furthermore, at the low temperature $\left(5^{\circ} \mathrm{C}\right)$ at which the flow behavior of the GSY samples was characterized, the hydrophobic interactions involved in casein association are very weak (Lee and Lucey, 2010).

The flow behavior index for the MCC-88 GSY was significantly higher than that of MCC-58 GSY and the strained control GSY at both inoculation levels (Table 5 ). It is likely that the higher acidity developed in the MCC-58 GSY led to greater aggregation of casein micelles and a more gel-like structure compared with MCC-88 GSY, which probably resembled a more concentrated suspension of casein micelles. We observed little to no significant effect of inoculation level on the flow behavior parameters of GSY (Table 5). The mag- 


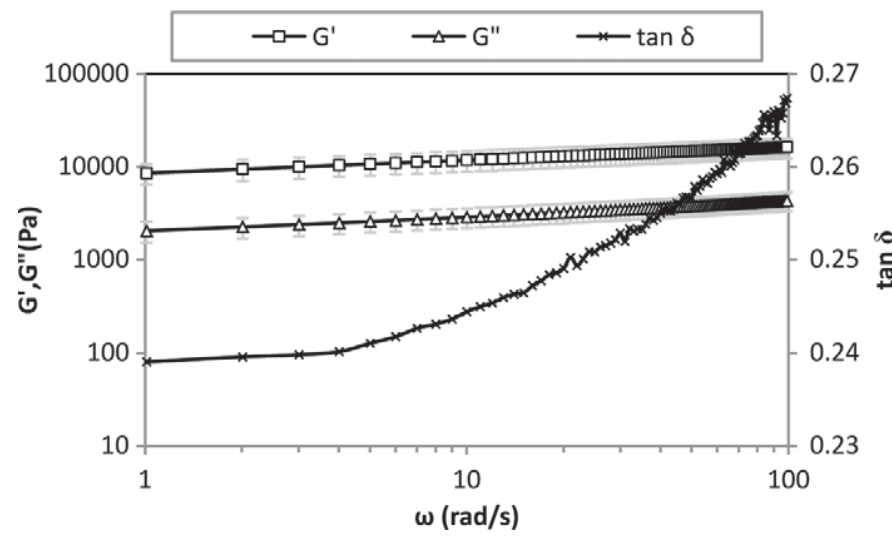

Figure 3. Frequency sweep for strained Greek-style yogurt (GSY) (control), at $0.7 \%$ strain, $5{ }^{\circ} \mathrm{C}$, and $0.04 \%$ inoculation level. Plotted are means of triplicate measurements $(\mathrm{n}=3)$; error bars represent 1 standard deviation. $\mathrm{G}^{\prime}=$ elastic modulus; $\mathrm{G}^{\prime \prime}=$ viscous modulus; tan $\delta=$ loss tangent; $\omega=$ frequency.

nitude of $K$ of the GSY samples was affected by solids content and chemical composition of GSY, with $K$ values increasing as TS content increased $(P<0.05$; Table $2)$. This is in agreement with other studies on flow behavior of stirred yogurts (Keogh and O'Kennedy, 1998; Celik et al., 2006; Penna et al., 2006; Ramirez-Sucre and Velez-Ruiz, 2013). Keogh and O'Kennedy (1998) found that $K$ values of stirred yogurt were mostly influenced by its protein content. Overall, the flow behavior parameters $\left(K, n\right.$, and $\left.\eta_{100}\right)$ of the MCC-58 GSY were not statistically different $(P>0.05)$ compared with the commercial strained GSY sample (Table 5).

Dynamic Rheological Properties of GSY. Dynamic rheological parameters $\left(\mathrm{G}^{\prime}, \mathrm{G}^{\prime \prime}\right.$, and tan $\left.\delta\right)$ were used to characterize the viscoelastic behavior of GSY samples. In the context of gel systems such as yogurt, dynamic strain sweeps can be used to differentiate weak gels and strong gels. Strong gels remain in the LVR over a greater strain range compared with weak gels (Steffe, 1996). Figure 3 shows an example of frequency sweep for the strained GSY (control) at the $0.04 \%$ inoculation level. Dynamic rheological testing revealed that $\mathrm{G}^{\prime}$ was greater than $G^{\prime \prime}$ for all GSY samples over the tested frequency range at both inoculation levels, which is indicative of a solid-like behavior. Another important viscoelastic parameter evaluated was $\tan \delta$, which can be used to indicate the extent of viscoelastic behavior for yogurt. A higher tan $\delta$ denotes a more viscous, liquid-like behavior, whereas lower tan $\delta$ values suggest a more solid-like behavior. The tan $\delta$ for all experimental GSY samples ranged from 0.23 to 0.30 , which is typical of a weak gel with a predominantly elastic behavior. No meaningful difference in viscoelastic behavior was observed between the commercial, strained, and MCC- fortified GSY samples at both inoculation levels which suggests that all samples had a similar gel structure.

The frequency dependence of the prevailing dynamic modulus, $\mathrm{G}^{\prime}$, as expressed by the slope of the modulus versus frequency curve $(m)$, was used as an indication of the type of gel structure and degree of interactions found within the yogurt matrices (Figure 4). All GSY samples exhibited a weak dependence of $\mathrm{G}^{\prime}$ on frequency, with $m$ ranging from 0.12 to 0.14 (Table 5 ), which indicates a soft solid with gel-like properties (Kasapis and Boskou, 2001). The amount of starter culture used for inoculation had no significant effect on the frequency dependence of $\mathrm{G}^{\prime}$ and thus on the type of gel network for the GSY samples.

The value of $\mathrm{G}^{\prime}$, which is an indication of gel firmness, was significantly higher $(P<0.05)$ for the strained GSY (control) compared with the MCC-fortified GSY (Figure 4). This difference could be attributed to differences in the degree of both covalent and noncovalent interactions in the 2 types of GSY as a result of a difference in chemical composition. Additionally, $\mathrm{G}^{\prime}$ values of the experimental control sample were significantly
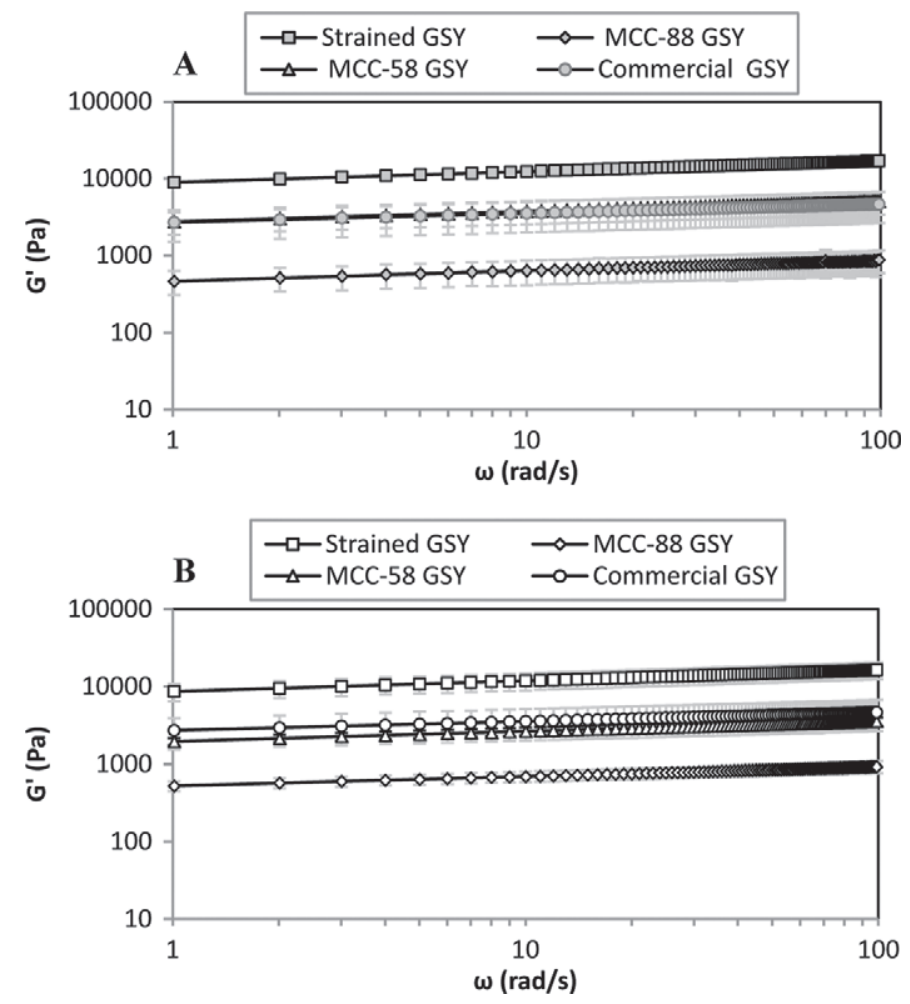

Figure 4. Frequency dependence of elastic modulus $\left(\mathrm{G}^{\prime}\right)$ for Greekstyle yogurt (GSY) samples at $5{ }^{\circ} \mathrm{C}$ and (A) $0.02 \%$ inoculation level; or (B) $0.04 \%$ inoculation level. Plotted are means of triplicate measurements $(\mathrm{n}=3)$; error bars represent 1 standard deviation. MCC-58 and MCC-88 GSY $=$ GSY fortified with micellar casein concentrate at 58 and $88 \%$ total protein, respectively. $\omega=$ frequency. 
higher $(P<0.05)$ than $\mathrm{G}^{\prime}$ of the commercial GSY sample. This may be attributed to a difference in the method used for whey removal. The experimental control sample was strained, whereas whey was removed by centrifugation for the commercial GSY sample. Abu Jdayil et al. (2002) also observed significant differences in rheological properties between concentrated yogurt samples that were subjected to whey removal by straining in cloth bags and centrifugal separation. Another reason for the observed difference could be the difference in the heat treatment conditions applied to the yogurt milk base before fermentation, which could have influenced the extent of denaturation of whey proteins and thus the extent of disulfide crosslink formation between $\kappa-\mathrm{CN}$ and $\beta$-LG (Lucey et al., 1998, 1999).

The $\mathrm{G}^{\prime}$ values of MCC-58 GSY were significantly higher $(P<0.05)$ compared with those of MCC-88 GSY. As discussed previously, this could be attributed to a difference in the solids and casein content of the 2 types of MCC-fortified GSY, which was likely to affect their microstructure. Marafon et al. (2011) reported that the microstructure of unfortified yogurt showed numerous large pores evenly distributed in the protein matrix, whereas the microstructure of yogurt fortified with sodium caseinate at similar protein content showed a more compact protein matrix, with fewer and smaller pores. The presence of a high numbers of pores in the microstructure of yogurt gels indicates a weaker gel (Lee and Lucey, 2004). In the current study, it was expected that the structure of the MCC-58 GSY would be more compact compared with MCC-88 GSY, which contributed to a stronger, firmer gel network in the former.

The $\mathrm{G}^{\prime}$ of the MCC-58 GSY was similar $(P>0.05)$ to that of the commercial GSY sample. This, combined with the observation that the 2 types of yogurt have virtually overlapping flow curves (Figure 1), suggests that the 2 types of yogurt have similar textural properties. This is significant because texture is a very important sensory attribute for consumer liking and acceptance of a yogurt product. Furthermore, we observed a correlation between the G' of GSY gels and their WHC. Lucey (2001) stated that gel networks with high modulus are able to prevent excessive syneresis. In this study, the MCC-fortified GSY had a significantly lower WHC ( $P$ $<0.05$ ) compared with its strained control counterpart, which suggests that MCC-fortified GSY may be more prone to syneresis than the experimental strained GSY. Among the 2 types of MCC-fortified GSY, MCC-58 GSY had a higher WHC compared with MCC-88 GSY (Table 5), which suggests that the former is likely to have a lower propensity for whey separation during storage.

\section{CONCLUSIONS}

Fortification of milk with MCC obtained by microfiltration is a promising alternative to the conventional make process of GSY by whey removal. Micellar casein concentrate with $58 \%$ protein might be a suitable source of micellar casein for milk fortification because the physical properties of the GSY fortified with MCC58 were similar to those of GSY manufactured by the conventional whey removal process. These findings can help GSY processors design appropriate conditions for alternative production methods of GSY by MCC fortification. Future work in this area will evaluate the sensory properties and shelf life of the GSY made by the alternate process compared with the traditional whey-removal process.

\section{ACKNOWLEDGMENTS}

The authors thank the New York State Milk Promotion Advisory Board for funding this research, and David Barbano's research group from Cornell University (Ithaca, NY) for supplying the MCC powder. We also thank Anne Sauer, Deepti Ananth, Wanyu Li, and Guoping Feng (Cornell University) for their help and assistance in different stages of this research. We acknowledge the kind assistance of Chr. Hansen Inc. (Milwaukee, WI), who donated the cultures for this work.

\section{REFERENCES}

Abu-Jdayil, B., and H. Mohameed. 2002. Experimental and modelling studies of the flow properties of concentrated yogurt as affected by the storage time. J. Food Eng. 52:359-365.

Abu-Jdayil, B., R. R. Shaker, and R. Y. Jumah. 2000. Rheological behavior of concentrated yogurt (Labneh). Int. J. Food Properties $3: 207-216$.

Abu-Jdayil, B., R. R. Shaker, and R. Y. Jumah. 2002. Rheological properties of a concentrated fermented product, Labneh, produced from bovine milk: Effect of production method. Int. J. Food Properties 5:667-669.

Affertsholt, T. 2009. Business Consulting Report: The Market for Dairy Ingredients Based on Separation Technology. Vol. 3A. Business Consulting, Aarhus C, Denmark.

Akalın, A. S., G. Unal, N. Dincki, and A. A. Hayaloglu. 2012. Microstructural, textural and sensory characteristics of probiotic yogurts fortified with sodium calcium caseinate or whey protein concentrate. J. Dairy Sci. 95:3617-3628.

Amatayakul, T., A. L. Halmos, F. Sherkat, and N. P. Shah. 2006. Physical characteristics of yoghurts made using exopolysaccharide producing starter cultures and varying casein to whey protein ratios. Int. Dairy J. 16:40-51.

AOAC International. 2000. Official Methods of Analysis. 17th ed. Method 972.16. AOAC International, Gaithersburg, MD.

Astley, M. 2013a. Acid whey? Not us! Greek yogurt firms distance themselves from environmental concerns. Accessed Jun. 7, 2013. http:// www.foodnavigator-usa.com/Manufacturers/Acid-whey-Not-us!Greek-yogurt-firms-distance-themselves-from-environmentalconcerns. 
Astley, M. 2013b. Don’t waste your acid whey! Arla concept turns byproduct into value-added dairy. Accessed Sep. 2013. http://www. dairyreporter.com/Ingredients/Don-t-waste-your-acid-whey!-Arlaconcept-turns-by-product-into-value-added-dairy.

Beliciu, C. M., and C. I. Moraru. 2011. The effect of protein concentration and heat treatment temperature on micellar casein-soy protein mixtures. Food Hydrocoll. 25:1448-1460.

Beliciu, C. M., A. Sauer, and C. I. Moraru. 2012. The effect of commercial sterilization regimens on micellar casein concentrates. J. Dairy Sci. 95:5510-5526.

Beshkova, D. M., E. D. Simova, G. I. Frengova, Z. I. Simov, and E. F. Adilov. 1998. Production of amino acids by yogurt bacteria. Biotechnol. Prog. 14:963-965.

Celik, S., I. Bakirci, and I. G. Sat. 2006. Physicochemical and organoleptic properties of yogurt with cornelian cherry paste. Int. J. Food Prot. 9:401-408.

Cerning, J. 1990. Exocellular polysaccharides produced by lactic acid bacteria. FEMS Microbiol. Rev. 7:113-130.

Chandan, R. C., and K. R. O'Rell. 2006. Yogurt plant: Quality assurance. Pages 256-259 in Manufacturing Yogurt And Fermented Milks. 1st ed. R. C. Chandan, Y. H. Hui, C. H. White, and A. Kilara, ed. Blackwell Publishing Ltd., Oxford, UK.

Courtin, P., and F. Rul. 2004. Interactions between microorganisms in a simple ecosystem: Yogurt bacteria as a study model. Lait $84: 125-134$.

Damin, M. R., M. R. Alacantara, A. P. Nunes, and M. N. Oliveira. 2009. Effects of milk supplementation with skim milk powder, whey protein concentrate and sodium caseinate on acidification kinetics, rheological properties and structure of nonfat stirred yogurt. Lebenson. Wiss. Technol. 42:1744-1750.

Degeest, B., and L. DeVuyst. 1999. Indication that the nitrogen source influences both amount and size of exopolysaccharides produced by Streptococcus thermophilus LY03 and modeling of the bacterial growth and exopolysaccharide production. Int. Dairy J. 65:28632870 .

Euromonitor International. 2012. Yoghurt and Sour Milk Products in the US. Accessed Oct. 28, 2013. http://www.portal.euromonitor. com/Portal/Pages/Search/SearchResultsList.aspx.

Farinde, E. O., T. O. Adesetan, V. A. Obatolu, and M. O. Oladapo. 2009. Chemical and microbial properties of yogurt processed from cow's milk and soymilk. J. Food Process. Preserv. 33:245-254.

Haque, A., R. K. Richardson, and E. R. Morris. 2001. Effect of fermentation temperature on the rheology of set and stirred yogurt. Food Hydrocoll. 15:593-602.

Harwalkar, V. R., and M. Kalab. 1986. Relationship between microstructure and susceptibility to syneresis in yoghurt made from reconstituted nonfat dry milk. Food Microstruct. 5:287-294.

Hodkinson, L. 2013. Category insight: Yogurt and chilled desserts. Accessed Oct. 28, 2013. http://www.gnpd.com/sinatra/gnpd/ category_page $/$ category_id $=7$ \#cat_review $=20011663$.

Hurt, E., J. Zulewska, M. Newbold, and D. M. Barbano. 2010. Micellar casein concentrate production with a $3 \times, 3$-stage, uniform transmembrane pressure ceramic membrane process at $50^{\circ} \mathrm{C}$. J. Dairy Sci. 93:5588-5600.

Isleten, M., and Y. Karagul-Yuceer. 2006. Effects of dried dairy ingredients on physical and sensory properties of nonfat yogurt. J. Dairy Sci. 89:2865-2872.

Karam, M. C., C. Gaiani, R. Barbar, C. Hosri, and J. Scher. 2012. Effect of dairy powder rehydration state on gel formation during yogurt process. J. Dairy Res. 79:280-286.

Kasapis, S., and D. Boskou. 2001. Rheological and sensory properties of popular Greek foodstuffs: A review. Int. J. Food Prot. $4: 327-340$

Keogh, M. K., and B. T. O'Kennedy. 1998. Rheology of stirred yogurt as affected by added milk fat, protein and hydrocolloids. J. Food Sci. 63:108-112.

Lee, W. J., and J. A. Lucey. 2004. Structure and physical properties of yogurt gels: Effect of inoculation rate and incubation temperature. J. Dairy Sci. 87:3153-3164.
Lee, W. J., and J. A. Lucey. 2006. Impact of gelation conditions and structural breakdown on the physical and sensory properties of stirred yogurts. J. Dairy Sci. 89:2374-2385.

Lee, W. J., and J. A. Lucey. 2010. Formation and physical properties of yogurt. Asian-australas. J. Anim. Sci. 23:1127-1136.

Lucey, J. A. 2001. The relationship between rheological parameters and whey separation in milk gels. Food Hydrocoll. 15:603-609.

Lucey, J. A., P. A. Munro, and H. Singh. 1999. Effects of heat treatment and whey protein addition on the rheological properties and structure of acid skim milk gels. Int. Dairy J. 9:275-279.

Lucey, J. A., M. Tamehana, H. Singh, and P. A. Munro. 1998. Effect of interactions between denatured whey proteins and casein micelles on the formation and rheological properties of acid skim milk gels. J. Dairy Res. 65:555-567.

Marafon, A. P., A. Sumi, D. Granato, M. R. Alcantara, A. Y. Tamime, and M. Nogueira de Olivera. 2011. Effects of partially replacing skimmed milk powder with dairy ingredients on rheology, sensory profiling, and microstructure of probiotic stirred-type yogurt during cold storage. J. Dairy Sci. 94:5330-5340.

Mohameed, H. A., B. Abu-Jdayil, and A. Al-Shawabkeh. 2004. Effect of solids concentration on the rheology of Labneh (concentrated yogurt) produced from sheep milk. J. Food Eng. 61:347-352.

Mulvihill, D. M., and M. P. Ennis. 2003. Functional milk proteins: Production and utilization. Pages 1175-1228 in Advanced Dairy Chemistry, Vol. 1: Proteins. 3rd ed. Kluwer Academic, New York, NY.

Nelson, B. K., and D. M. Barbano. 2005. A microfiltration process to maximize removal of serum proteins from skim milk before cheese making. J. Dairy Sci. 88:1891-1900.

Neviani, E., G. Giraffa, A. Brizzi, and D. Carminati. 1995. Amino acid requirements and peptidase activities of Streptococcus salivarius ssp. thermophilus. J. Appl. Bacteriol. 79:302-307.

Nsabimana, C., B. Jiang, and R. Kossah. 2005. Manufacturing, properties and shelf life of Labneh: A review. Int. J. Dairy Technol. $58: 129-137$.

Peng, Y., M. Serra, D. S. Horne, and J. A. Lucey. 2009. Effect of fortification with various types of milk proteins on the rheological properties and permeability of nonfat set yogurt. J. Food Sci. 74:C666-C673.

Penna, A. L., A. Convertti, and M. Olliveira. 2006. Simultaneous effects of total solids content, milk base, heat treatment temperature and sample temperature on the rheological properties of plain stirred yogurt. Food Technol. Biotechnol. 44:515-518.

Prentice, J. H. 1992. Yogurt. Pages 132-132 in Dairy Rheology: A Concise Guide. VCH Publishers, New York, NY.

Puvanenthiran, A., R. P. W. Williams, and M. A. Augustin. 2002. Structure and visco-elastic properties of set yoghurt with altered casein to whey protein ratios. Int. Dairy J. 12:383-391.

Ramirez-Sucre, M. O., and J. F. Velez Ruiz. 2013. Physicochemical, rheological and stability characterization of a caramel flavored yogurt. Lebenson. Wiss. Technol. 51:233-241.

Remeuf, F., S. Mohammed, I. Sodini, and J. P. Tissier. 2003. Preliminary observations on the effects of milk fortification and heating on microstructure and physical properties of stirred yogurt. Int. Dairy J. 13:773-782.

Sauer, A., I. Doehner, and C. I. Moraru. 2012. Steady shear rheological properties of micellar casein concentrates obtained by membrane filtration as a function of shear rate, concentration and temperature. J. Dairy Sci. 95:5569-5579.

Sauer, A., and C. I. Moraru. 2012. Heat stability of micellar casein concentrates as affected by temperature and $\mathrm{pH}$. J. Dairy Sci. 95:6339-6350.

Shah, N. P. 2003. Yogurt: The product and its manufacture. Pages 6252-6260 in Encyclopedia of Food Sciences and Nutrition, Vol 10. 2nd ed. B. Caballero, L. C. Trugo, and P. M. Finglas, ed. Academic Press, London, UK.

Skriver, A., J. Holstborg, and K. B. Qvist. 1999. Relation between sensory texture analysis and rheological properties of stirred yogurt. J. Dairy Res. 66:609-618. 
Sodini, I., F. Remeuf, S. Haddad, and G. Corrieu. 2004. The relative effect of milk base, starter, and process on yogurt texture: A review. Crit. Rev. Food Sci. Nutr. 44:113-137.

Steffe, J. F. 1996. Oscillatory testing. Pages 313-324 in Rheological Methods in Food Process Engineering. 2nd ed. Freeman Press, East Lansing, MI
Tamime, A. Y., and R. K. Robinson. 2007. Yoghurt: Science and Technology. 3rd ed. CRC Press, Boca Raton, FL.

van Marle, M. E., and P. Zoon. 1995. Permeability and rheological properties of microbially and chemically acidified skim-milk gels. Neth. Milk Dairy J. 49:47-65. 